\title{
E-PROCUREMENT AS A WAY TO PROTECT THE PUBLIC INTEREST ${ }^{1}$
}

\author{
Marina V. Shmeleva \\ Saratov State Law Academy, Saratov, Russian Federation
}

\begin{abstract}
Introduction: the paper is devoted to the study of legal mechanisms in the area of public procurement, which can ensure the protection of the public interest and respect for fundamental human rights and freedoms. Modern international law requires that the public procurement regulations include the standards for the protection of fundamental human rights. There are serious loopholes in the Russian procurement legislation regarding the application of human rights protection standards in the performance of contractual obligations. For this purpose, the author reveals the hierarchy of interests of all the subjects of legal relations in the area of procurement and the main ways of violations of human rights and the public interest. By means of methods of scientific knowledge, first of all, comparative jurisprudence, the system of public procurement in comparison with the contract system of the USA was considered. The paper also uses specific methods of scientific knowledge, including: system-structural, formallogical, as well as special legal methods of normative interpretation. Results: it is pointed out that the lowest-price competition often encourages States to support unscrupulous contractors who violate the fundamental human rights, fail to comply with the occupational safety standards and pay low wages. In particular, in Russia, the law does not allow obliging customers to only enter into a contract with those procurement participants who are ready to ensure compliance with the labor rights. In such a situation, human rights could only be protected by ensuring transparency in the procurement process. In turn, achieving transparency of procurement is only possible with the use of digital technologies. Conclusions: according to the results of the study, it should be assumed that the current procurement rules in Russia at each stage need to be improved in terms of filling in the loopholes in the human rights procurement standards aimed at ensuring respect for fundamental human rights. The active use of IT-technologies is required for the development and implementation of self-executing agreements in a single information system.

Key words: public procurement, e-procurement, digitalization of procurement, human rights mechanisms in procurement, procurement legislation.
\end{abstract}

Citation. Shmeleva M.V. E-Procurement as a Way to Protect the Public Interest. Legal Concept, 2019, vol. 18, no. 4, pp. 61-66. (in Russian). DOI: https://doi.org/10.15688/lc.jvolsu.2019.4.8

\section{ЭЛЕКТРОННЫЕ ЗАКУПКИ КАК СПОСОБ ЗАЩИТЫ ОБЩЕСТВЕННЫХ ИНТЕРЕСОВ ${ }^{1}$}

\author{
Марина Владимировна Шмелева \\ Саратовская государственная юридическая академия, г. Саратов, Российская Федерация
}


прежде всего сравнительного правоведения, рассмотрена система государственных закупок в сравнении с контрактной системой США. Кроме того, в работе использованы частные методы научного познания, в том числе системно-структурный, формально-логический, а также специально-юридические методы нормативного толкования. Результаты: отмечено, что конкуренция самой низкой цены часто побуждает государства оказывать поддержку недобросовестным подрядчикам, нарушающим основополагающие права человека, не соблюдают нормы охраны труда и платят низкую заработную плату. В частности, в России закон не позволяет обязывать заказчиков при проведении закупок заключать контракт только с теми участниками закупок, которые готовы обеспечивать соблюдение трудовых прав. В такой ситуации защиту прав человека можно осуществить только путем обеспечения прозрачности закупочного процесса. В свою очередь достижение этой прозрачности возможно исключительно при использовании цифровых технологий. Выводы: действующие в России правила закупок на каждом этапе нуждаются в усовершенствовании в части восполнения пробелов в правозащитных стандартах закупок, направленных на обеспечение соблюдения основных прав человека. Требуется активное использование ИТ-технологий в целях разработки и внедрения самоисполняемых контрактов в единую информационную систему.

Ключевые слова: государственные закупки, электронные закупки, цифровизация закупок, правозащитные механизмы в закупках, законодательство о закупках.

Цитирование. Шмелева М. В. Электронные закупки как способ защиты общественных интересов // Legal Concept $=$ Правовая парадигма. -2019 . - T. 18, № 4. - C. 61-66. - DOI: https://doi.org/10.15688/lc.jvolsu.2019.4.8

\section{Введение}

Система государственных закупок является эффективным инструментом концентрации необходимых ресурсов (интеллектуальных, материальных, технологических, трудовых) для осуществления поставленных перед государством задач. Она оказывает определяющее влияние на выполнение основных функций государства, удовлетворение общественных потребностей, реализацию приоритетных национальных проектов.

Очевидно, что государственные закупки осуществляются в целях удовлетворения разнонаправленных общественных и частных интересов. С одной стороны, они проводятся в интересах общества, государства и организаций с государственным участием, с другой - потенциальных поставщиков (исполнителей, подрядчиков). Более того, закупки могут выступать эффективным средством защиты основных прав и свобод каждого отдельного человека, например, когда с их помощью обеспечивается защита интересов профсоюзных организаций или соблюдение прав широкого круга лиц в области охраны труда, запрета на принудительный труд и соблюдения трудовых норм.

Поскольку интересы у всех субъектов правоотношений в сфере государственных закупок имеют разнонаправленный характер, зачастую они могут вступать в противоречие друг с другом. Так, заказчик стремится к полному и качественному удовлетворению своих потребностей за минимальную цену (в европейских странах - за оптимальную), участник закупки - к извлечению прибыли любыми доступными способами, в том числе путем поставки некачественного товара, государство к максимальной эффективности закупок и экономии бюджетных средств.

Данное противоречие объяснимо и не вызывает удивления: участник закупки желает при максимизации доходов минимизировать издержки, а заказчику, как правило, необходимо выполнить государственное задание и, как следствие, делать это приходится в условиях ограниченного бюджетного финансирования.

На сегодняшний день отсутствует методика определения значимости разнонаправленных общественных интересов и чаще всего приоритет того или иного интереса решается каузально, что на практике приводит к неизбежному конфликту интересов.

В связи с этим представляется необходимым на доктринальном уровне оптимально гармонизировать общественные и частные интересы в сфере государственных закупок, а на законодательном - установить иерархию значимости таких интересов.

\section{Иерархия интересов в государственных закупках}

Стандарт защиты прав человека действует во многих нормативных правовых актах Российской Федерации, включая Конституцию 
РФ, ГК РФ, ГПК РФ, АПК РФ, УК РФ, УПК РФ. Оно заложено и в международных правовых актах. Так, «Всеобщая декларация прав человека» ограничивает осуществление прав человека с целью обеспечения должного признания и уважения прав и свобод других и удовлетворения требований общественного порядка и общего благосостояния [2, ст. 29].

Цель регламентирования интересов в закупках - это создание такой конфигурации прав и обязанностей всех субъектов правоотношений в сфере государственных закупок, при которой максимально обеспечены целостность и сохранность прав отдельного физического или юридического лица, не ущемляющих интересы государства и общества.

Российское закупочное законодательство постоянно находится в поиске приемлемого баланса интересов всех субъектов правоотношений в сфере государственных закупок, в том числе это подтверждается и ст. 31 Закона о контрактной системе [4], согласно которой закрепляется принцип недопущения конфликта интересов между участниками закупки и заказчиком. Указанный принцип выражается в качестве одного из единых требований, предъявляемых ко всем без исключения участникам закупки.

Таким образом, не ставя перед собой невыполнимой задачи по достижению в закупках тождества общих и частных интересов, постараемся выявить разумное и эффективное сосуществование интересов в сфере закупок на всеобщее и личное благо.

Одним из способов гармонизации частных и общественных интересов является осмысление и законодательное закрепление иерархии интересов.

В отечественной литературе выделяется иерархия интересов, которая может быть применима и к сфере закупок [1, с. 105].

Во-первых, общественные интересы. К ним относятся: охрана окружающей среды, обеспечение обороны страны, безопасности государства, общественного правопорядка и охрана труда.

Во-вторых, государственные интересы. Закупки выступают одним из направлений деятельности государства, напрямую влияющим на доступ граждан к основным услугам, таким как образование, здравоохранение и др.
Любой гражданин как пользователь результатов государственных закупок должен обладать правом подать жалобу на некачественно оказанную услугу (плохо отремонтированную детскую площадку, некачественную дорогу и так далее), а уполномоченный орган государственной власти - оперативно и объективно рассмотреть жалобу и принять решение, в том числе провести проверку по этому факту.

Россия уже имеет опыт создания достаточно эффективного механизма процедурного контроля в сфере государственных закупок. Такой же механизм должен быть создан и в отношении контроля за содержательными результатами закупок. Сегодня эти функции фактически никем не осуществляются, хотя нормативно закреплены за органами финансового контроля.

В-третьих, охрана частных интересов. В частности, к относятся: права участников закупки на равный доступ к закупочным процедурам, справедливую и объективную оценку поданных заявок, отсутствие дискриминации и необоснованных ограничений конкуренции по отношению к ним.

В-четвертых, общественные и частные интересы, связанные с реализацией предпринимательских прав (всех остальных, за исключением естественных прав человека). Так, каждый участник закупки имеет интерес в получении прибыли при участии в государственных закупках.

\section{Нарушения прав человека в сфере государственных закупок}

Рассмотрим первичные интересы в сфере закупок - общественные. Выработке представленной в настоящей работе позиции отчасти способствовал опыт законодательства США, в котором в случае столкновения частных и общественных интересов также отмечена тенденция к предпочтению интересов большинства.

Современные нормы международного права требуют, чтобы нормативное регулирование государственных закупок включало стандарты уважения к человеческим правам. В российском закупочном законодательстве они не разработаны и не внедрены, и, соот- 
ветственно, заказчиками и участниками закупок не выполняются.

В качестве современных примеров нарушений прав человека, связанных с проведением государственных закупок приведем следующие.

1. Подрядчики, которые при исполнении обязательств по контракту не соблюдают трудовое законодательство. Так, субподрядчик на заводе в Тихуане (Мексика), занимающийся изготовлением брони и тактического снаряжения, не выплачивал заработную плату за сверхурочную работу своим сотрудникам [5]. Таким образом, государственные средства направлялись в пользу недобросовестного лица, нарушающего основные человеческие права на отдых и справедливую оплату труда.

2. Подрядчики, которые при исполнении обязательств по контракту, заключенному по результатам проведенных торгов, нарушают права профсоюзных организаций. Так, субподрядчик, участвуя в выполнении крупного оборонного заказа по пошиву униформы для государственных служащих в регионе Теуакан (Мексика), после организации акции протеста профсоюзом уволил 13 его лидеров. После того как рабочие завода проголосовали за присоединение к профсоюзу, субподрядчик закрыл завод, а затем занес в черный список более 400 человек, поддержавших профсоюз от рабочих мест на других заводах [5].

3. Подрядчики, исполнение контрактных обязательств которыми связано с использованием рабства, принудительного труда и торговли людьми. Так, Демократическая Республика Конго выступает ведущим экспортером минералов, таких как кобальт и тантал, необходимых для производства электронных продуктов. Все добывающие отрасли в Конго изобилуют рабством, принудительным трудом и торговлей людьми. Большинство стран мира, в том числе США, ежегодно приобретают указанные минералы для создания электроники для органов исполнительной власти [6].

4. Подрядчики, которые не соблюдают нормы охраны труда, в результате чего гибнут люди. Так, производство одежды для военноморского флота, сухопутной армии и воздушных сил США осуществлялось на одном из самых опасных заводов в мире. В процессе исполнения обязательств по контракту на пошив рубашек с морскими логотипами для военноморского флота США в здании произошел пожар, в котором погибли 112 рабочих [7].

Приведенные выше примеры ясно показывают, что подрядчики, готовые конкурировать за правительственные контракты, нарушют права человека, начиная гонку вне всяких разумных правил. Есть веский аргумент в пользу того, что государства являются соучастниками преступлений против прав человека, поскольку они устанавливают правила этой гонки и пользуются результатами закупок.

На наш взгляд, важно привести два ключевых фактора, способствующих процветанию вышеуказанной деятельности при исполнении государственных контрактов и приводят к бесчеловечным результатам.

Первый фактор - осуществление закупки, в котором главным критерием является низкая цена. В России, к сожалению, в данной сфере традиционно происходит исключительно ценовая конкуренция. Более того, аукционный крен системы закупок только усиливается с каждым годом: доля электронных аукционов с 2017 по 2018 г. выросла с 65,8 до $69,6 \%$.

Второй фактор - отсутствие квалификационных требований к участникам закупки. Действующее законодательство не разделяет их на квалифицированных и неквалифицированных. Дополнительные требования к участникам закупки предусмотрены только для определенных категорий закупок.

Проведенный анализ закупочного законодательства и административной практики ФАС позволяет прийти к выводу, что для обеспечения максимальной эффективности закупок и достижения экономии необходимо обеспечить доступ к закупкам максимального количества участников. При этом доступность закупочного процесса должна быть обеспечена не для производителя, а для посредника, так как, по мнению представителей ФАС и судебных органов, участник закупки не обязан иметь в наличии товары или необходимые трудовые и материальные ресурсы вплоть до выполнения контракта [3].

На практике это привело к тому, что торги выигрывают профессиональные тендерные игроки, которые затем перепродают контракт 
реальным исполнителям, юридически оставаясь стороной контракта, но фактически $100 \%$ отдавая на соисполнение (субподряд), в том числе организациям, также участвовавшим, но не победившим в торгах.

\section{Выводы}

Анализ международного опыта позволяет сделать вывод, что конкуренция самой низкой цены часто побуждает государства оказывать поддержку недобросовестным подрядчикам, которые нарушают основополагающие права человека, не соблюдают нормы охраны труда и платят низкую заработную плату. В такой ситуации защиту прав человека можно обеспечить только путем обеспечения прозрачности закупочного процесса.

Именно посредством использования ИТ-технологий можно осуществлять мониторинг за деятельностью подрядчиков и субподрядчиков путем обеспечения большей открытости закупочной деятельности. Идеальный вариант предполагает, что отношения по государственному контракту должны быть самоисполняемыми, то есть все данные о процессе должны передаваться автоматически, поскольку при ручном вводе нельзя исключить человеческий фактор и гарантировать, что пользователь системы указал достоверные данные.

Для максимального использования потенциала цифровой революции в России необходимо также совершенствовать законодательство в части восполнения пробелов в правозащитных стандартах закупок, направленных на обеспечение соблюдения основных прав человека, приводить квалификацию участников закупок в соответствие с требованиями новой экономики и обязать поставщиков по государственным контрактам гарантировать обязательное раскрытие информации о местах выполнения работ (оказания услуг), производства товаров хотя бы в тех случаях, где существует доказанный риск нарушений прав человека.

\section{ПРИМЕЧАНИЕ}

${ }^{1}$ Исследование выполнено при финансовой поддержке РФФИ в рамках научного проекта № 19-
011-00163 «Механизм гражданско-правового регулирования в сфере цифровых государственных и муниципальных закупок».

The study was funded by RFBR in the framework of the scientific project No. 19-011-00163 "Mechanism of civil regulation in the field of digital state and municipal procurement".

\section{СПИСОК ЛИТЕРАТУРЫ}

1. Вавилин, Е. В. Общественный интерес в гражданском праве / Е. В. Вавилин // Седьмой Пермский конгресс ученых-юристов (г. Пермь, 18-19 ноября 2016 г.) : сб. науч. ст. - М. : Статут, 2017. -592 с.

2. Всеобщая декларация прав человека // Организация Объединенных Наций. - Электрон. текстовые дан. - Режим доступа: https://www.un.org/en/ universal-declaration-human-rights (дата обращения: 20.08.2019). - Загл. с экрана.

3. Решение Арбитражного суда г. Москвы от 30.11.2017 по делу № А40-136645/17. - Доступ из справ.-правовой системы «КонсультантПлюс».

4. Федеральный закон от 05.04.2013 № 44-Ф3 «О контрактной системе в сфере закупок товаров, работ, услуг для обеспечения государственных и муниципальных нужд» (в ред. от 27.12.2018) // Coбрание законодательства Российской Федерации. 2013. - № 14. - Ст. 1652 ; 2018. - № 53 (часть I). Ст. 8444.

5. Claeson, B. S. Subsidizing Sweatshops II 39 / B. S. Claeson ; ed. by S. Brown. - [S.1.] : SweatFree Communities, 2009. $-61 \mathrm{p}$.

6. U.S. Government is Tops in IT Spending but with how much waste? // Face the Facts USA. Electronic text data. - Mode of access: http:// www. faceth efactsusa.org/facts/feds-spend-74billionit\#sthash.HJH0h V0J.dpuf (date of access: 10.02.2019). - Title from screen.

7. Mosk, M. Bangladesh Factory Fire: Patterns for Marine Corps Sweats, Tank Tops Found in Ashes // ABC News. - 2012. - Dec. 4. - Electronic text data. Mode of access: http://abcnews.go.com/Blotter/ bangladesh-factory-firepatterns-marine-corps-sweatstank/story? $\mathrm{id}=17875010 \&$ singlePage $=$ true (date of access: 05.02.2019). - Title from screen.

\section{REFERENCES}

1. Vavilin E.V. Obshchestvennyy interes v grazhdanskom prave [Public Interest in Civil Law]. Sedmoy Permskiy kongress uchenykhyuristov (g. Perm, 18-19 noyabrya 2016 g.) : sb. nauch. st. [Seventh Perm Congress of Legal Scholars] (Perm, 18-19 November 2016). Collection 
of Scientific Articles]. Moscow, Statut Publ., 2017. $592 \mathrm{p}$.

2. Vseobshchaya deklaratsiya prav cheloveka [Universal Declaration of Human Rights]. Organizatsiya Obyedinennykh Natsiy [United Nations]. URL: https://www.un.org/en/universaldeclaration-human-rights (accessed 20 August 2019).

3. Reshenie Arbitrazhnogo suda g. Moskvy po delu № A40-136645/17 [Decision of the Moscow Arbitration Court of 30 November 2017 in Case no. A40136645/17]. Access from Reference Legal System "KonsultantPlus"

4. Federalnyy zakon ot 05.04.2013 № 44-FZ «O kontraktnoy sisteme v sfere zakupok tovarov, rabot, uslug dlya obespecheniya gosudarstvennykh i munitsipalnykh nuzhd» (v red. ot 27.12.2018) [Federal Law № 44-FZ of 05 April 2013 “On the Contract System in the Procurement of Goods, Works and
Services for State and Municipal Needs" (As Amended on 27 December 2018)]. Sobranie zakonodatelstva Rossiyskoy Federatsii [Collected Legislation of Russian Federation]), 2013, no. 14, art. 1652; 2018, no. 53 (part I), art. 8444.

5. Claeson B. S. Subsidizing Sweatshops II 39. SweatFree Communities, 2009. 61 p.

6. U.S. Government is Tops in IT Spending but with how much waste? Face the Facts USA. URL: http://www.facethefactsusa.org/facts/feds-spend-74billionit\#sthash.HJH0hV0J.dpuf(accessed 10 February 2019).

7. Mosk M. Bangladesh Factory Fire: Patterns for Marine Corps Sweats, Tank Tops Found in Ashes. $A B C$ News, 2012, December 4. URL: http://abcnews.go.com/ Blotter/bangladesh-factory-firepatterns-marine-corpssweats-tank/story?id $=17875010 \&$ singlePage $=$ true (accessed 5 February 2019).

\section{Information about the Author}

Marina V. Shmeleva, Candidate of Sciences (Jurisprudence), Doctoral Student, Associate Professor, Department of Civil Law, Saratov State Law Academy, Volskaya St., 1, 410056 Saratov, Russian Federation, civil2012@mail.ru, https://orcid.org/0000-0002-1628-8366

\section{Информация об авторе}

Марина Владимировна Шмелева, кандидат юридических наук, докторант, доцент кафедры гражданского права, Саратовская государственная юридическая академия, ул. Вольская, 1, 410056 г. Саратов, Российская Федерация, civil2012@mail.ru, https://orcid.org/0000-0002-1628-8366 